\title{
LABORATORY TEST RIG FOR EXAMINING AGGREGATE MINING FROM SEABED USING THE AIRLIFT METHOD
}

\author{
Czesław Dymarski \\ Tomasz Pająk \\ Gdańsk University of Technology, Poland
}

\begin{abstract}
The use of the Airlift method for transporting the mined aggregate from the seabed to the deck of the mining ship is an alternative for presently used solutions, such as suction pumps or scoop transport for instance. Building the laboratory test rig was preceded by tests in natural conditions. The rig was designed in such a way as to model these conditions as close as possible, and to have potential for further development.
\end{abstract}

Keywords: Airlift method, Airlift test rig, deep-level mining

\section{INTRODUCTION}

The Airlift method makes use of gas as the carrier of energy converted to the work of water and aggregate transport. In previous tests, performed in natural conditions, pure oxygen was used for this purpose but it will be replaced with air in model tests.

For the purpose of solid substance transport, the flows in vertical pipelines can be divided, based on the criterion of the number of flowing phases, into two- or three-phase gaswater-aggregate mixtures. Initially, the two-phase mixture was examined to determine the flow velocity of the liquid medium. This parameter value was needed for defining initial operating conditions of the examined device in the mathematical model. An attempt was made to assess the effect of gas fraction change in the liquid phase volume, and to determine minimal gas amounts needed to start aggregate mining at a given level. Then, tests were performed with the three-phase mixture to determine the effect of water flow velocity and gas pressure on the mining rate of the aggregate of known granulation and shape from a given depth.

Fig. 1 presents examples of different flows in the water-air mixture. They differ by the course of gas phase extension, the task of which is to create the mixture velocity which will be able to generate sufficiently large resistance on aggregate grains to elevate them up. This task is best reached in the first type of flow, i.e. the bubble flow, for which the contributions of gas fraction and liquid fraction are close to each other along the entire length of the vertical pipeline segment. Other flow types: annular flow, slug flow, and churn flow can be a source of differences between results recorded for the same operating parameters. These types of flow are unfavourable for effective elevation of the mined aggregate. One of the planned research tasks will be determining conditions which ensure obtaining the most favourable flow. 

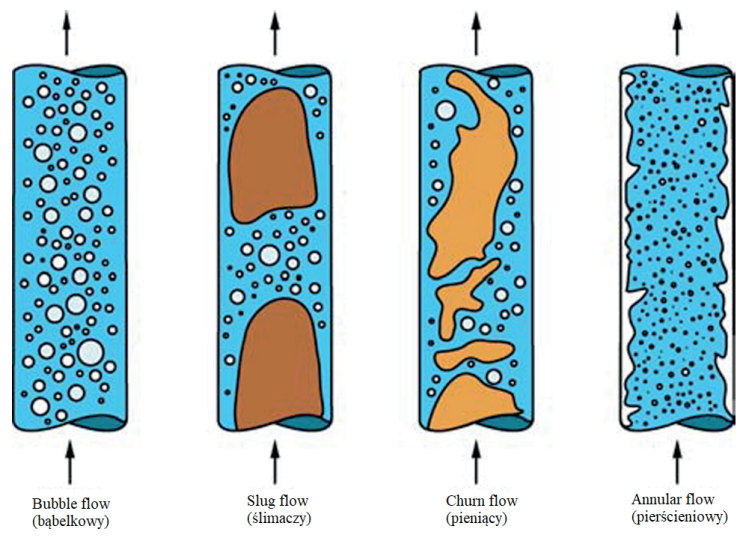

Fig. 1. Types of flows in vertical pipelines [1]

In the case of three-phase flows, the flow of gas and liquid looks similar. Three- measurement series are planned to measure the output of the elevated aggregate for operating conditions differing by various parameters, including:

- air flow rate,

- granulation of the elevated gravel,

- elevation height,

- distance of the mining head from the aggregate,

- distance of the air delivery point to the mining head.

As a result, operating efficiency characteristics will be worked out as functions of the above parameters. The results of these tests will make it possible to verify the developed mathematical models and the associated computer codes.

\section{BUILDING THE LABORATORY TEST RIG}

The test rig consists of three units. The first unit comprises a lower tank having the form of vertical cylinder presented in Figs. 2 and 3.

In this unit, the following elements can be named:

1 - base, made of stainless steel,

2 - pipe of $\varnothing 400 \mathrm{~mm}$ in diameter, made of PMMA (polymethylmethacrylate),

3 - cover, made of stainless steel,

4 - extension with flange, made of stainless steel,

5 - mining pipe of $\varnothing 50 \mathrm{~mm}$, made of PMMA,

6 - return pipe of $\varnothing 100 \mathrm{~mm}$, made of PMMA,

7 - O-ring type seals,

8 - M6 bolts made of zinc covered material,

9 - M10 pins made of stainless steel.

The cover and the base are screwed together with $8 \times \mathrm{M} 10$ pins and relevant nuts with washers. Moreover, to ensure tightness between the stainless base and cover on the one hand, and the pipe made of PMMA on the other hand, use was made of polyurethane adhesive sealing mass APP - PU 50.

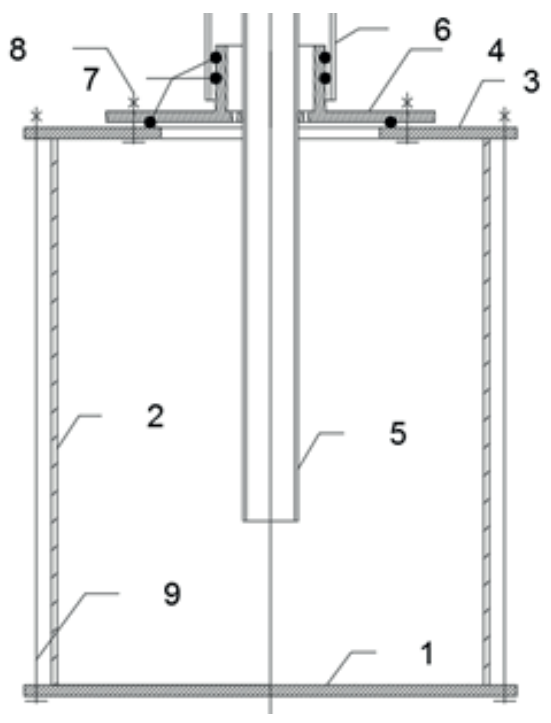

Fig. 2. Lower tank cross section

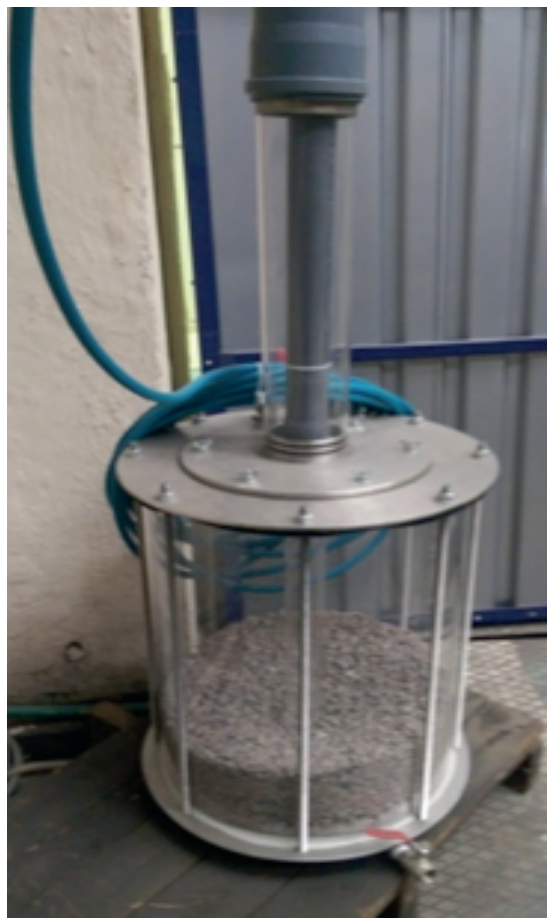

Fig. 3. View of lower tank

Ball valves mounted in the base and in the cover can be easily connected via a quick-release coupling to the water supply pipe or to the drain pipe to deliver water to or remove it from the lower tank and the entire system.

The system consisting of cover 3 and extension 4 with flange is intended to provide opportunities for rig development. A hole of $ø 250 \mathrm{~mm}$ in diameter is made in the cover 2 to allow testing of mining pipes of up to $ø 200 \mathrm{~mm}$. The space between these pipes should allow water to return to the lower tank. Tightness was obtained by the O-ring seal and pressing of the extension flange to the cover 3 with $6 x \mathrm{M} 6$ bolts. 
Fig. 3 shows the excess part of the hose delivering the air from the internal compressed air system to the mining pipe. The connection point of this hose is situated above the extension 4 , at the place where the mining pipe made of PCW is connected with the pipe made of PMMA (5).

In the upper part of the system, a tank made of PMMA is situated, see Fig. 4. Aggregate and water are transported to this tank. It comprises the following elements:

1 - container made of PMMA,

2 - crown cap with holes, made of PCW,

3 - mining pipe made of PCW.

Tight connection between the container 1 and the crown cap 2 is ensured by acrylic silicone, which at the expected pressures is sufficient to prevent against water losses. Moreover, the return pipe was also sealed with silicone. The container was made of PMMA plates, which were glued together using the acrylic adhesive ACRIFIX. Silicone was also used at each corner of plate connection places.

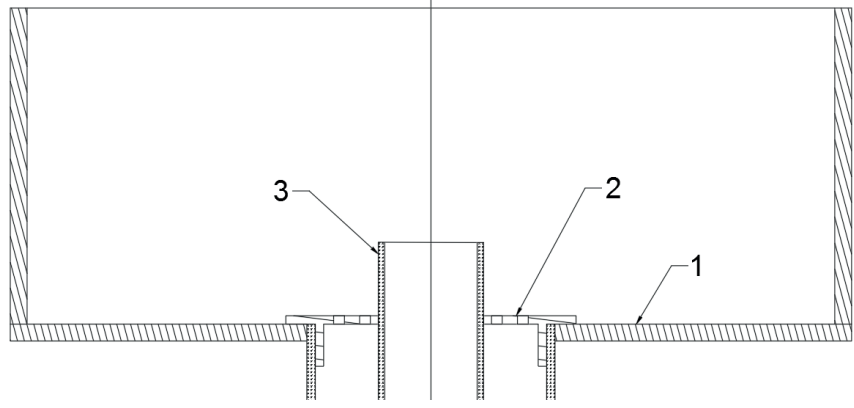

Fig. 4. Upper tank cross section

Both tanks are connected together via two pipelines, i.e. mining and return pipeline made of PCW. A hose which delivers air to the mining head is introduced between these two pipelines. Tightness of all pressed connections is additionally ensured by the use of acrylic silicone.

The measurements are performed using a container with scale, to which the mining pipeline delivers the mixture of water and air with gravel. This way the amounts of the mined gravel and water can be compared at different pressures. It also enables to assess the proportion of gravel in the transported water or, alternatively, the mining time for a given volume and different pressures to define optimal operating conditions.

The laboratory test rig was built based on the experience gained in real tests. Fig. 5 shows the mining output from a pipeline in which we can observe turbulent water 1 and gravel grains 2 of different granulation, while Fig. 6 shows the results of the test performed from the catamaran, at depth of $10 \mathrm{~m}$. These tests differed by the mining method. At the platform the gravel was scattered over the bottom, while during mining from the catamaran, a gravel container suspended on strips 3 as used. Water with gravel was transported via the mining pipeline 4 to the container 5 .

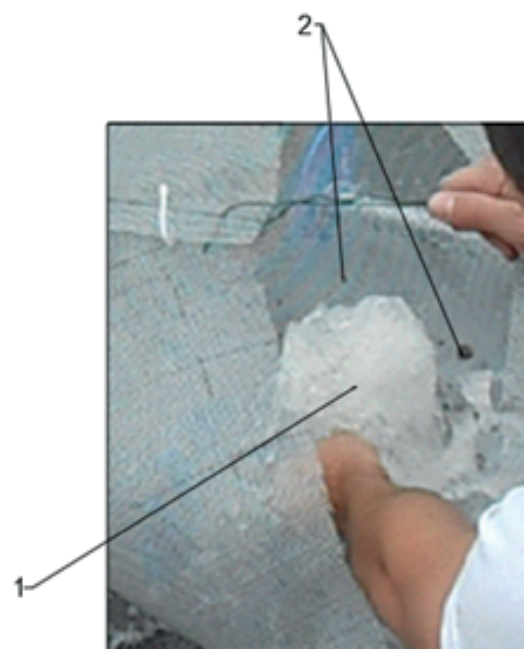

Fig. 5. Photo of mining output from platform

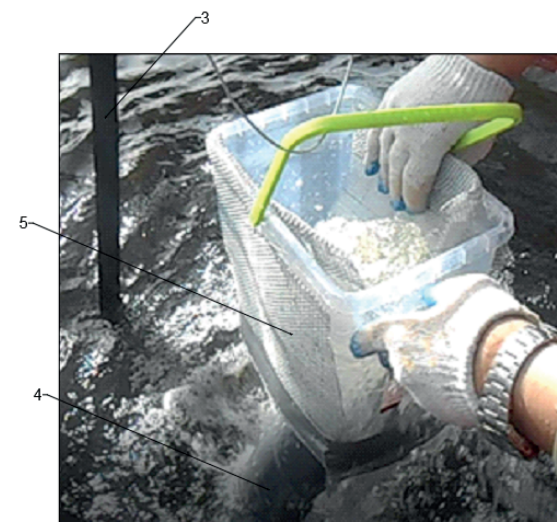

Fig. 6. Photo of mining output from catamaran

Fig. 7 shows the lowered pipe which sucks gravel from the prepared basket and sand from the water region bed. The tests were performed from a boat, on the water region of $8 \mathrm{~m}$ in depth.

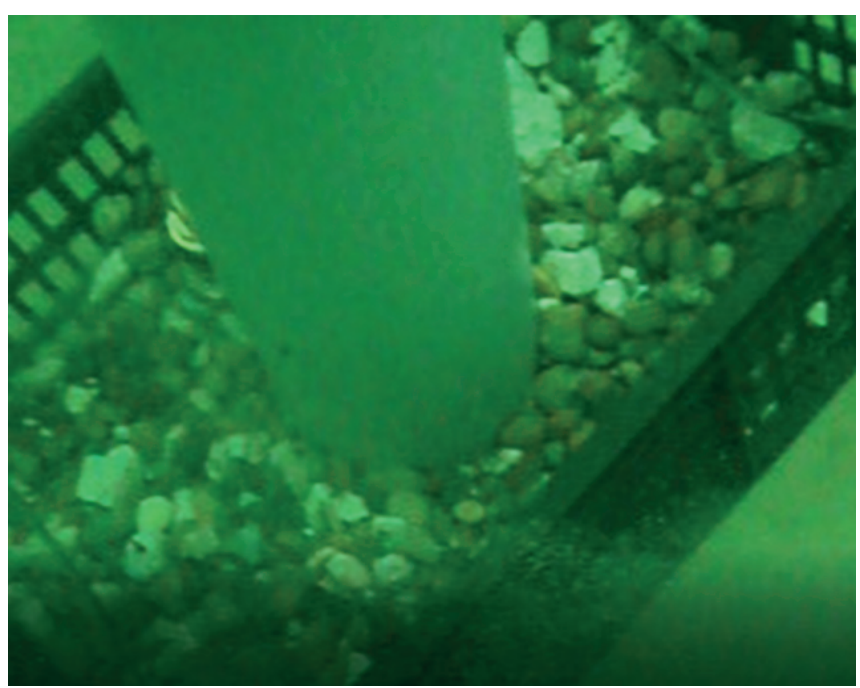




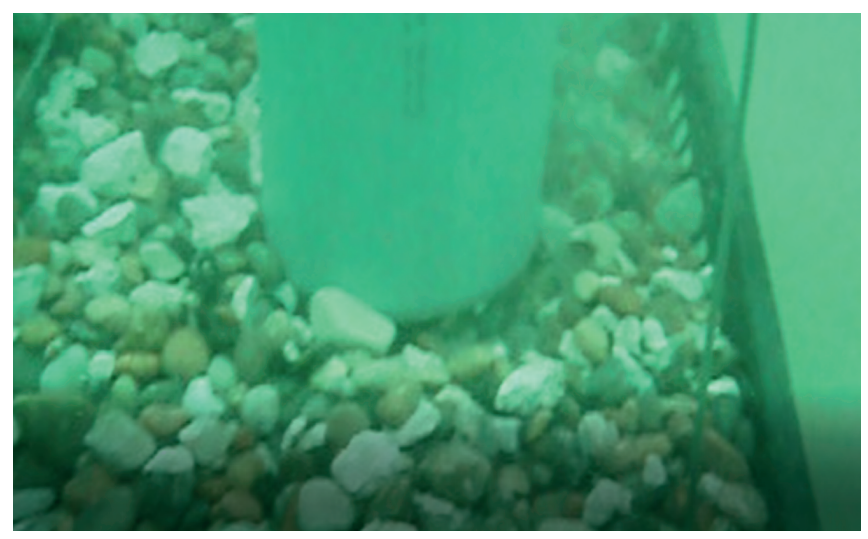

Fig. 7. Photos taken by diver

\section{OPERATING CONDITIONS AVAILABLE ON THE RIG}

Model test were performed in the laboratory owned by the Faculty of Ocean Engineering and Ship Technology, Gdansk University of Technology. The maximal available height for these tests is approximately equal to $8 \mathrm{~m}$. The maximal pressure available in the laboratory compressed air installation is $800 \mathrm{kPa}$, which is fully sufficient for model tests. There is also a possibility to analyse the effect of the quality of liquid medium, i.e. salt or fresh water, as well as to perform tests with a pipeline inclined at an angle, to analyse its effect on operating conditions and mining output.

The tests have made it possible to assess the effect of aggregate grain type and size. Gravel granulation and quality of grain edges can affect the results of tests. There is a possibility to use different types of aggregate and grain sizes.

The distance of the gas phase connection point can be controlled, and this point can be situated beyond the lower tank. Moreover, the pressure hose can be inserted inside the lower tank to supply the mining pipe with air from there.

\section{ISSUES}

When designing the test rig, a number of issues were recognised which were to be solved to ensure correct rig operation.

The first interesting issue was water delivery and reception. Initially, a method was proposed to deliver water by flooding the upper tank and letting it flow gravitationally to the lower tank via a system of mining pipelines. After a brief analysis, a valve was added in the lower tank upper cover, through which the lower tank can be the filled in such a way that the aggregate layer to be mined is not deformed by the water flowing from the upper tank. The water was drained from the system using a tap mounted additionally in the lower cover. This tap was connected to a garden hose which led the water to a drain sump in the floor. This, however, required moving the entire structure slightly up and placing the lower tank on two supports, the height of which provided access to the tap and allowed connecting it to the drain hose.

The next issue recognised when designing the rig was ensuring tightness of the lower tank, while simultaneously preserving its potential for development and mobility of the entire rig. Initially, elastic rubber which was impermeable for water was used for this purpose. However, taking into consideration the material used for covers, a decision was made that sufficient tightness will be ensured by adhesive sealing mass which can be easily removed after rig disassembly, using a small sharp knife for instance and abrasive paper to remove its remnants. The lower part of the tank was also glued and sealed on both sides using the same mass. Fig. 8 shows sealing of the lower tank structure, between the base and the cylindrical part of the tank.

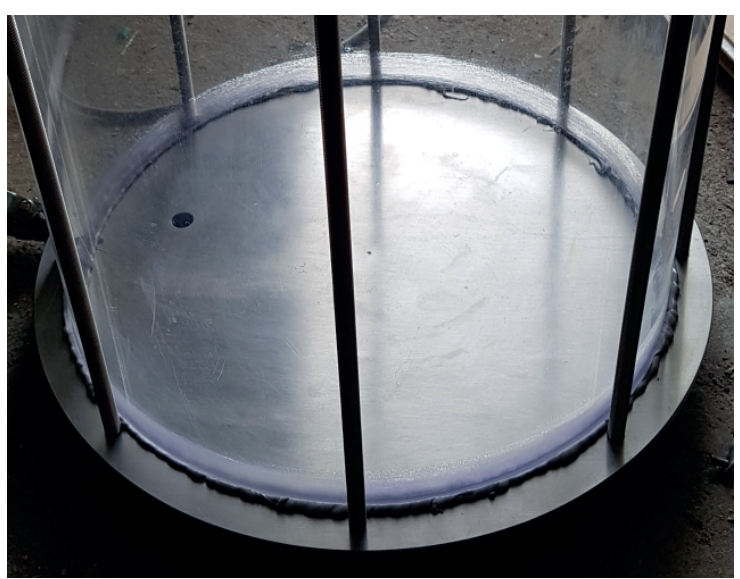

Fig. 8. Sealing of lower tank

A substantial issue which required deeper analysis to solve was the measuring procedure which should ensure satisfactorily high accuracy. In the case of three-phase mixture, performing a continuous measurement is rather problematic. Taking this into consideration, a decision was made to perform first the measurement of water elevation velocity for the two-phase flow, without the aggregate. For this purpose, a measuring container with scale was used, which was filled with elevated water in a given time interval at different air pressures. The results obtained in this measurement will be compared with those recorded during the three-phase flow measurement, with the aggregate.

The next parameter affecting the efficiency of aggregate mining is the distance of the mining head from the gravel layer. To study this effect, the amounts of water and aggregate will be changed during the complete mining cycle executed for constant air pressure. The measured values of this distance will make the basis for working out aggregate mining characteristics as functions of this parameter, and thus determining its optimal values.

In the described laboratory test rig the distance of the mining head from the aggregate layer can be measured using a scale mounted at the end of the mining pipeline. The measured height difference will give an opportunity to check how this distance changes with the inlet pressure level 
change, thus providing basic pieces of information concerning operating conditions and their optimisation, including selection of the range of values assumed for optimal mining.

To get a wider insight into the mining phenomenon and its operating conditions, an opportunity of rig development for different diameters of mining pipelines was provided. Decreasing the pipeline diameter does not bring substantial structure changes, while its increasing is limited to $\varnothing 200 \mathrm{~mm}$, which still gives a wide analysing potential, taking into account the mining elevation height obtainable in laboratory conditions.

\section{RESULTS OF TESTS}

Within the framework of the tests, time was measured from the appearance of the first mined grain to complete mining of all grains. Additionally, one test included mass measurement of the gravel mined for different pressures.

The model tests were performed for constant pressures and for increasing pressures, which means that mining was executed at the pressure increasing from $0 \mathrm{~Pa}$ to the current measurement value (Fig.9)

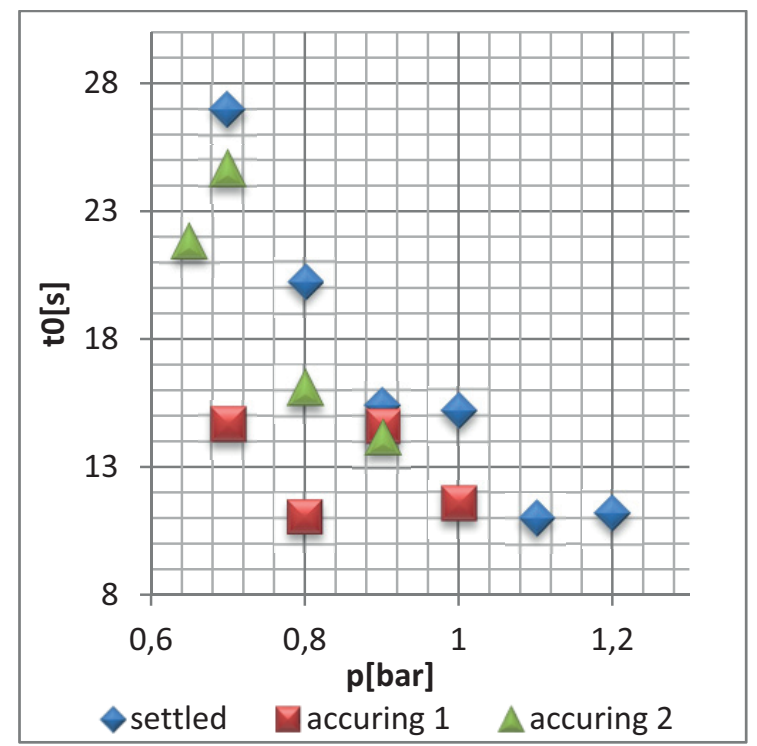

Fig. 9. Time (t0) of appearance of first aggregate grain vs. applied working pressure $(p)$ for different operating conditions

During the examination with the aid of a stop-watch and video recording, the time t0 needed by the gravel grain to cover, in the mining pipeline, the distance from the lower tank to the control container was measured for different pressures. Three measurements were performed: two for increasing pressure and one for constant pressure, which has resulted in modernisation of the rig.

Fig. 10 shows the time tc needed for complete mining of all gravel grains as function of the pressure $\mathrm{p}$ used for mining. The time was measured from the beginning of mining to the end of gravel elevation, at unchanged position of the mining pipeline.

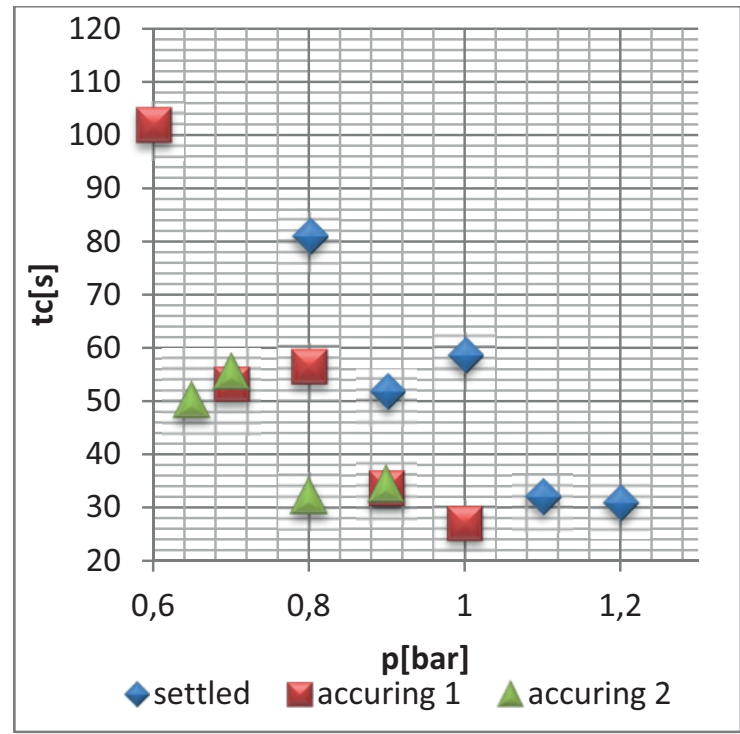

Fig. 10. Time (tc) of complete mining vs. applied working pressure ( $p$ ) for different operating conditions

Fig. 11 shows the amount of mined gravel as a function of pressure changes, for steady-state operation.

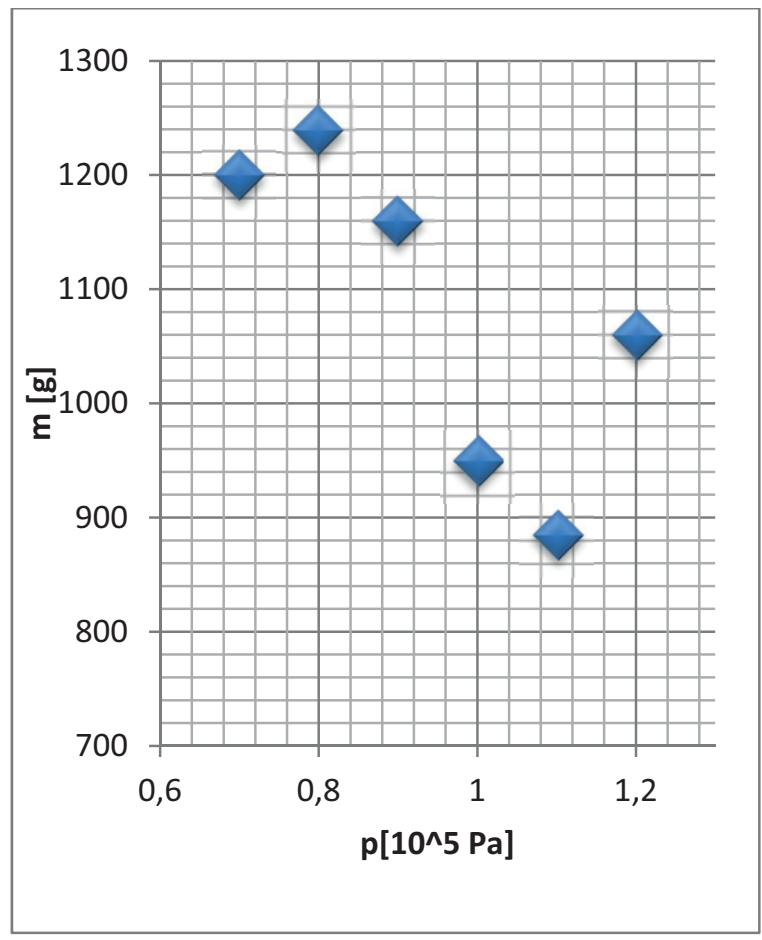

Fig. 11. Mass $(m)$ of mined gravel vs. applied working pressure ( $p)$

\section{CONCLUSIONS}

The performed model study aimed at: obtaining results close to those recorded in real conditions, taking into consideration the size effect on the mining output, determining the effect of pressure level and type of water on the flow and resultant mining output, and checking the effect 
of the above initial conditions on the distance between the suction pipe and the mined material in the lower tank. This latter aspect was an important motivation for building the test rig. Additionally, an attempt was made to assess the expansion coefficient of the gas phase for changing inlet pressures.

The Airlift method is an alternative for other well-known and commonly used methods of aggregate mining from the bed of a water region, for instance methods making use of suction pumps or scoops. The only limiting factor in the Airlift method is expansion of gas phase. Once proper operating conditions are established, the method provides opportunities to mine aggregates from much larger depths than those available in traditional methods.

As can be seen in the diagrams, pressure increase leads to the decrease of time needed for gravel grain mining, with respect to both the appearance of the first grain, and the total time of mining at a given place. Further tests will be performed for identical pressure ranges but they will include presentation of maximal pressures and comparison of time changes.

The diagram illustrating mass changes of the mined gravel reveals irregularity for different pressures, which indicates that the pressure strongly affects the output. The interpretation of these results is difficult as it should take additionally into consideration gravel granulation, the shape of the hopper created during mining, as well as the distance of the suction pipe and its shape. The presented preliminary measurements have revealed that the pressure increase leads to the change of system operation efficiency, which is believed to result from the influence of the pressure level on the type of the generated flow of liquid and the resultant transport of aggregate. Further research, to be performed for a larger number of measurement variants with the aid of more accurate measuring equipment, is expected to determine more precisely relations between pressure and other parameters of aggregate mining.

\section{BIBLIOGRAPHY}

1. Mudde, R.F., Gravity-driven bubbly flows. Annu. Rev. Fluid Mech., 2005. 37: p. $393-423$.

2. J Sobota, S Boczarski, L Petryka, M Zych, Measurement of velocity and concentration of nodules in vertical hydrotransport., 2005.

3. P Vlasak, Z Chara, B Kysela, J Sobota Flow behaviour of coarse-grained slurries in pipes., 2011.

4. DOB Jones, S Kaiser, AK Sweetman, CR Smith; Biological responses to disturbance from simulated deep-sea polymetallic nodule mining; 2017

5. C Starke, PR Bérubé; Reuse of Air for Return Activated Sludge Pumping in Submerged Membrane Bioreactors; 2016
6. A Oueslati, A Hannachi, M Elmaaoui; Effect of Air Humidification on the Pumping Efficiency of Water in a Packed Column Humidifier; 2015

7. A Oueslati, A Hannachi, M Elmaaoui; Effect of Air Humidification on the Pumping Efficiency of Water in a Packed Column Humidifier; 2015

\section{CONTACT WITH THE AUTHORS}

\author{
Czesław Dymarski \\ e-mail:cpdymars@pg.gda.pl \\ Tomasz Pająk \\ e-mail:tompajak@pg.gda.pl \\ Gdansk University of Technology \\ Faculty of Ocean Engineering and Ship Technology \\ Department of Marine Mechatronics \\ 11/12 Narutowicza St. \\ 80 - 233 Gdańsk \\ Poland
}

